\title{
PERSPECTIVAS DA ARQUEOLOGIA PÚBLICA NO BRASIL E EM CUBA
}

\section{ENTREVISTADA}

\section{Lourdes Dominguez}

Pesquisadora da Oficina del Historiador de Habana Vieja, Cuba, e professora visitante da Universidade Estadual de Campinas.

Contato: chinopelon36@gmail.com.

\section{ENTREVISTADORA}

Isabela Backx

Aluna de mestrado do Programa de PósGraduação na linha de História Cultural da Unicamp e pesquisadora colaboradora do Laboratório de Arqueologia Pública da Unicamp.

Contato: isabela_backx@yahoo.com.br.

\section{RESUMO}

A presente entrevista tem como objetivo analisar como a Arqueologia Pública é entendida pela intelectual Lourdes Dominguez, reconhecida estudiosa cubana que desenvolve diversos trabalhos em parceria com universidades brasileiras. No decorrer do texto, aborda-se também a trajetória acadêmica da professora, assim como o desenvolvimento da Arqueologia Pública em Cuba e as aproximações possíveis entre esse país e o Brasil.

Palavras Chave: Arqueologia Pública, Brasil, Cuba.

A Arqueologia Pública vem a cada ano alcançando novas possibilidades e perspectivas. Desenvolvendo-se como um campo de estudos interdisciplinar, tem como um de seus principais objetivos possibilitar a interação da sociedade na produção do conhecimento científico, envolvendo esta nos trabalhos de recuperação e preservação de sua própria história. Para entender melhor essas questões, a professora Lourdes Dominguez cedeu-nos gentilmente uma entrevista que auxiliará nessa reflexão, além de fornecer-nos uma breve perspectiva sobre o desenvolvimento dessa ciência em outro país e de possíveis interações entre Cuba e Brasil.

Lourdes Dominguez é atualmente pesquisadora da Oficina del Historiador de Habana Vieja, em Cuba, e desde meados do ano dois mil vem ao Brasil anualmente para atuar como professora visitante na Universidade Estadual de Campinas, além de desenvolver diversos projetos com outras instituições. Dentre estes, ministra cursos no Laboratório de Arqueologia Pública (Unicamp), palestras na Universidade Federal de Pelotas (UFPel) e na Universidade Federal de Alfenas (UNIFAL), entre outras. 
Isabela Backx: Para empezar, podrías contarnos un poco acerca de tu carrera académica. ¿Cómo empezaron tus estudios en Arqueología?

Lourdes Dominguez:

Te voy a contar que fue algo muy interesante, de pura casualidad. Yo me interesaba mucho por todo lo que es el problema indígena en América latina, sobre todo en las primeras etapas. Desde el triunfo de la revolución eso fue una cosa nueva, que me impactó. O sea, las comunidades que vivían todavía, sus papeles de desarrollo histórico en América, etc. Todas esas cosas me gustaron, y eso era muy difícil de estudiar en mi país en ese momento. Años 60, acabábamos de empezar todo el proceso revolucionario, y fue difícil encontrar algo que me ayudara, pues la sociología no la habían abierto la universidad. Traté de estudiar otras carreras pero por razones de obrería, o sea, un examen que no podría hacer, la matemática que soy muy mala y todo eso, por eso resolví estudiar historia.

La historia me ha abierto un mundo inmenso, y tuve la segunda suerte de tener un compañero que era arqueólogo. Un colega de un estudio que me introdujo dentro de un departamento que se creaba nuevo dentro de la academia de ciencia. Bueno, la academia de ciencia como órgano investigativo, no como reunión de académicos. Ahora es diferente. En aquel momento, ese organismo que se organizó en Cuba, que se llamaba Academia de Ciencias de Cuba, era un emporio de investigaciones, y se había abierto una parte para el estudio de Arqueología, que la dirigía el doctor Ernesto Tabio y que colaboraba con el doctor José Manuel Guarch. Mi amigo, mi hermano, estudiamos juntos, el al final no terminó la carrera de historia. Fue hacer su doctorado por línea directa en Unión Soviética, pero nos quedamos muy amigos y él fue quien me introdujo dentro del área arqueológica de estudios. Me gusto muchísimo. La situación más terrible fue que por ejemplo, el señor que dirigía aquella institución, un hombre mayor, muy culto, muy buen arqueólogo, un hombre que había trabajado en Perú y en diferentes lugares, tenía un concepto de las mujeres muy desagradable, y cuando fui - una muchachita - a decirle "a mi me interesa trabajar aquí," lo que me dijo fue: "Arqueología no es para mujeres".

Yo me sentí tan defraudada, además todo ese proceso revolucionario de los inicios del proceso cubano fue muy interesante en el sentido de que el papel de la mujer era muy bien reconocido, estábamos muy influidos del feminismo y toda esa serie de cosas que se dan entonces. $Y$ aquella respuesta de aquel hombre, que yo lo consideraba un sabio, decirme que esa especialidad, esa ciencia, no era para mujeres. Fue como si me tiraran un jarro de agua arriba, entonces figúrate que no me quedó mas remedio de que decirle: "está bien, si usted dice eso yo no digo nada, se acabó." Pero para dentro de mi dije: "bueno este es el momento en que empieza de verdad el interés por Arqueología". Y continué yendo a todas las reuniones, a todas las conferencias, a todas las cosas, y a los dos años y pico de aquella situación ya yo estaba trabajando en ese sitio. Porque entré como historiadora, y al otro día ya estaba haciendo excavaciones y bueno, fue todo un desarrollo, al final el se hizo un gran amigo mío y fue prácticamente mi padre, vamos a decirlo así. Conversábamos mucho acerca de la especialidad, de los conceptos, teníamos muchas discusiones científicas, y compartimos muchos libros. Fue un gran amigo al final, y junto al otro amigo mío también, José Manuel Guarch, que es un arqueólogo de primera podríamos decir que el primer arqueólogo cubano con un pensamiento claro sobre la Arqueología cubana -, fue mi amigo hasta su receso, cuando perdí un amigo y un hermano. 


\section{I.B.: Actualmente eres pesquisadora de la Oficina del Historiador de La Habana, Cuba. Cuén- tanos un poco acerca de los trabajos que se desarrollan en esta institución, y cómo las actividades arqueológicas se insieren en ella.}

L.D.:

Tenemos que hacer un poquitico de historia. En todo lo que es el trabajo anterior, o sea, antes de entrar en la Oficina del Historiador, nosotros trabajábamos en la Academia de Ciencia. Esta Academia de ciencia que te decía yo, que era un organismo - era, porque ya no existe -investigativo, o sea, de grupos de investigadores que trabajaban diferentes líneas de la geografía, de la Arqueología, de la literatura, de diferentes cosas. Todo eso formaba un gran elefante, podríamos decir, sobre estudios generales. Y la Arqueología se estudiaba porque había un curso de Arqueología dentro de allí, que fueron cursos medios, básicos y superiores, con presentación de tesis y con todas esas cosas. Pero se hacía diariamente. Había almacenes, había trabajo de laboratorio, y tú tenías que pasar por todo. $\mathrm{O}$ sea, el arqueólogo que nada más se sienta en una mesa a escribir, ese no es arqueólogo. Tú tienes que entrar y trabajar en un laboratorio, desde empezar a lavar una pieza, saber cuáles son las características de las piezas, de los materiales, porque los tienes que hacer, cómo los tienes que guardar, buscar toda esa información. Yo tuve esa suerte de hacer el trabajo en esa forma. Y además, lo estudié dentro de la propia institución. Después fui a desarrollar algunos aspectos más a la Unión Soviética, a otros países como a Estados Unidos, pero ya después de haberme formado como un arqueólogo con todas las etapas que hay que conformar-se para que puedas después tu dirigir una excavación, tener criterios de cómo vas a guardar las piezas, de que qué tu quieres con las piezas, qué tu quieres con la excavación. Porque la excavación no es hacer un hoyo por gusto, tú tienes que crear las condiciones, buscar una estrategia, buscar la condicionante que te lleve a ese aspecto para entonces poder entender cómo desarrollar una excavación y que esa excavación tenga valores, valores que después se pasen en algún libro, alguna clase.

Entonces yo tuve esa suerte. Allá trabajé todo lo que es la parte aborigen, o sea, todo lo que es los aborígenes cubanos, porque mi jefe - aquel señor que te conté entendía que los arqueólogos tenían que ser capases de trabajar lo mismo: la parte indígena y la parte colonial. O sea, tendrían que ser completos, con un desarrollo completo, con un criterio completo de que es lo mismo hacer una temporada de trabajo industrial, en un ingenio azucarero, o en un promontorio, o sea, que había una mistura de todas estas cosas, pero también te permitía a ti tener un conocimiento amplio de todos esos aspectos, a conocer sobre todo la prehistoria cubana, desde los más antiguos hasta los más modernos, el contacto, todo eso. Yo me formé en todas esas cosas, entonces es mi manera de trabajar. Ya después tuve que dirigir ese departamento cuando el falleció. Tuve que dirigir ese departamento por dieciséis años, y eso para mí fue algo importante porque logré muchas cosas que yo entendía que debían hacerse en el estudio de Arqueología, en el trabajo arqueológico. Pero también fueron para mi dieciséis años de menos, porque la tarea burocrática no te permite tener ni estudio, ni trabajo, etc. Pero bueno, había que hacerlo, y no había en ese momento otra persona que estuviera con posibilidades o con criterios, los demás estaban estudiando, etc. Yo había ya terminado mi doctorado, y entonces continué ese trabajo hasta el año 94, en que decidí aposentarme. Porque ya estaba 
en tiempo, yo tenía ganas de descansar y no quería ser más dirigente de ese proceso, porque entendía que estaba perdiendo mis años mejores de formación.

Entonces me aposenté, jubilé, fui a trabajar a otro lugar, y entré en la Oficina del Historiador de la Ciudad, que era la oficina que organizaba toda la restauración de la Habana Vieja, que después fue declarada Patrimonio de la Humanidad. En esa Oficina del Historiador hay un gabinete de Arqueología, o sea, un organismo, un pequeño lugar - no tan pequeño, hoy ya está grande - que tiene un museo donde están todas o la mayoría de las piezas que se han sacado de la Habana Vieja y algunas cosas también del resto de la isla de Arqueología aborigen. Y tiene un grupo de trabajadores que auxilian al plan maestro, o sea, lo que es el plan maestro para realizar a partir de los cánones establecidos por la Carta de Venecia, de 64, que todo trabajo de restauración debe llevar consigo una excavación arqueológica. Esa es la tarea específica. Toda esa parte de la Habana Vieja, que es un gran espacio, tiene sus inmuebles clasificados por etapas y por valores, y van siendo restaurados. A medida que esa restauración comienza, un grupo de Arqueología comienza a realizar los trabajos establecidos en eso. Eso es Arqueología Histórica. Muy pocas veces se encuentra algo que puede ser clasificado como Arqueología Aborigen, pero a veces se da, porque la Habana está situada arriba de un área arqueológica prehispánica que no se ha encontrado. O sea, no podemos decir que nosotros hemos encontrado el yacimiento o el sitio donde estuvieron los aborígenes que vivieron en los alrededores de la Habana. No se ha podido encontrar porque también está tremendamente urbanizada, y es muy difícil hacer el trabajo ahora. No tenemos algunos materiales sofisticados, o sea, equipos sofisticados para poder detectar eso. Entonces hay que seguir haciendo lo que se está haciendo hasta ahora. Mi trabajo dentro de eso es asesoramiento. $\mathrm{O}$ sea, revisar los planes de trabajo, revisar todo, los lugares de excavación, etc; y cualquier duda o cualquier problema que haya para los compañeros.

\section{I.B.: ¿Qué entiendes por Arqueología Pública?}

L.D.:

Mira para mí el término es un término no usual en Cuba. De todas maneras, nosotros hemos estado haciendo un trabajo que indiscutiblemente es Arqueología Pública. O sea, todo lo que se trabaja en la Habana Vieja está totalmente compenetrado con la población que vive en ese lugar, porque una de las situaciones específicas que ha tratado de tener mi jefe, el doctor Eusebio Leal Spengler, que es el que ha ideado todo ese andamiaje de la Oficina del Historiador de la Ciudad, siempre piensa que sin los moradores de la ciudad, sin que la gente comparta sus propios criterios y ayude a trabajar en los museos y en las áreas de trabajo no hubiera absolutamente nada. Pues nosotros hemos estado haciendo Arqueología Pública hace muchos años, y no nos hemos enterado que se llamaba Arqueología Pública. Ahora estamos desarrollando ese término a partir verdaderamente de las concepciones, de la gestión patrimonial que se está realizando en la Oficina, y la gestión con los moradores de esa área, pues es un área que está llena de museos, se considera que es una "Ciudad Museo", pero no una ciudad muerta, si no una ciudad que vive. Los moradores quedan viviendo adentro de esa ciudad, a veces hay un museo en la primera planta y en la segunda planta hay gente a vivir, hay familias viviendo. $O$ sea, se cambian mucho los conceptos y por eso es que tienen mucha relación con la gente que vive en todos esos lugares. 


\section{I.B.: ¿Cuáles son las perspectivas actuales de la Arqueología Pública en Cuba?}

L.D.:

Bueno, fíjate, las perspectivas son tremendas. Es una ciudad antigua, una ciudad que fue amurallada, que tiene mucho espacio para trabajar. Ya encontramos una gran cantidad de museos en inmuebles, y ya están establecidos los de mayor valor a partir del plan maestro, donde se determinaron los que más valor tenían o los que estaban en más posibilidades de destrucción, y fueron los que tuvieron prioridad, y todavía consideramos que hay otras partes, o sea, estamos en la tercera parte de cuatro. Estamos en una tercera parte de un trabajo que está prácticamente concluido. Lo que pasa es que acuérdate que el trabajo patrimonial no se termina nunca, porque tú tienes que mantenerlo. O sea, tú no puedes reconstruir un inmueble y dejarlo, porque si lo dejas, a los tres o cuatro años está igual que cuando lo encontraste. Ahí es donde se gasta más dinero, ahí es donde se desarrolla más esfuerzo, y entonces eso hay que tenerlo en cuenta, tú no puedes hacer y hacer y hacer, escavar, escavar y escavar. El otro problema grande que le pasa a todos los arqueólogos es: "donde ponemos el material," entonces ya se está estudiando en algunos momentos qué materiales se quedan dentro del lugar que estamos excavando, con sus debidas referencias, con su debido material. Cuantas cantidades de cosas, qué es lo que se saca de los materiales, si se cuantifican, si se estudian, si se llevan para un laboratorio. Estamos en esas decisiones, en esas disquisiciones, que son muy difíciles, pero que son de una importancia tremenda, porque hay una necesidad inmensa en el mundo completo de tomar decisiones de lo que se va a hacer con los materiales. O sea, las excavaciones se dan y son toneladas de materiales, y esas toneladas de materiales tú tienes que darles científicamente una solución para su empaque, para su manutención, para su estancia en algún lugar futuro, porque la Arqueología como toda ciencia, sigue adecuándose a nuevas perspectivas, a nuevos trabajos, y a veces es necesario volver atrás en una excavación que en un momento determinado se hicieron algunas cosas, pero que ahora, con una sistemática de trabajo nueva, es muy necesario volver otra vez a trabajar con los materiales antiguos. Por eso la importancia de los materiales muy bien definidos, muy bien ordenados, muy bien estructurados, para tu puedas sacarles frutos no solamente en el momento que lo está haciendo, si no en un futuro para otras personas o para ti mismo. Esa es la disyuntiva que tenemos en este momento.

\section{I.B.: ¿A cuánto tiempo realizas trabajos en colaboración con universidades brasileñas? ¿Y cómo surgió esa oportunidad?}

L.D.:

Bueno voy a empezar por cómo surgió la cosa: conocí al doctor Pedro Paulo Funari en un congreso del World Archaeological, el que se dio en Barquisimeto, Venezuela. Fue el primer congreso fuera de Europa, el World Archaeological Congress. Yo fui de esas casualidades de la vida, había dinero en Cuba y me mandaron para el congreso. Allí estaban algunos amigos míos, venezolanos, que los quiero muchísimo, Mario Sanoja y Iraida Vargas, unos de los promotores de la Arqueología Social. En ese congreso se habló mucho de Arqueología social. Y bueno, estábamos un día en un recreo y conocía a Pedro Paulo, que ya había creo que terminado su doctorado, yo estaba por hacer el mío, y nos identificamos con nuestros trabajos. El hablaba muy bien el español, y yo 
de portugués todavía no sé nada, y conversamos muchísimo. Después terminó el congreso, cada uno regresó a su lugar, y no existían todavía los correos electrónicos, y fue eso. Pasó el tiempo, y como dos años o tres después de eso, yo estaba en Puerto Rico y ya estaba el correo electrónico funcionando, y en un attachment que me mandaron a mí de correo, venia el correo de Pedro Paulo, y yo le escribí. Después de eso, reanudamos nuestra amistad, el me pidió mi currículo y me dijo que si yo quería podría venir a Brasil, que tenían posibilidades de becas, etc, y no le hice mucho caso al principio, porque pensé como siempre que las becas son muy difíciles, son muy problemáticas a veces, etc. Pero bueno, yo le mande todos mis papeles y, para resumir la cuenta, todo funcionó. Yo regresé de Puerto Rico a Cuba, estuve unos meses y se dio el primer viaje aquí a Brasil con la beca. Estuve aquí en primera vez creo en el año dos mil o en noventa y nueve. Yo sé que de esa visita al $M A E$, de esa visita que hicimos en São Paulo, aquí en Campinas y todo, surgió la invitación al Congreso de $\mathrm{SAB}$, y el doctor José Luiz de Morais, que era el director del MAE en ese momento, me invitó a ese congreso, que fue verdaderamente exitosísimo, en organización, trabajo, conocer a la gente, pudimos todos colaborar, estábamos todos en un solo lugar donde pudimos conversar muchísimo. Ahí pude conocer a miles de compañeros que conocía solamente por carta. Fui después también a Brasília a dar una conferencia en el IPHAN, porque la señora María Elisa Costa, que era la que dirigía en ese momento el IPHAN, era amiga de un hijastro mío. Bueno, fue toda una cosa muy agradable. Resumiendo la cuenta, después de esa buenísima entrada vino la segunda beca, y de esa segunda, hasta hoy FAPESP ha tenido la gentileza de concederme esa beca, e yo de tratar también de hacer todo lo más posible para no solamente demostrar que la beca está funcionando, pero demonstrar que yo también ya me siento parte del trabajo que se hace en Brasil con Arqueología.

Ya estoy a diez u once años viniendo sistemáticamente, y me quedo a veces dos meses, a veces tres, en dependencia de los compromisos que tenga en Cuba o que haya aquí. Por ejemplo, este año fueron tres meses porque estaba previsto ir a Florianópolis, al Congreso de $S A B$, y después hay que complementar otra serie de cosas, de libros, conferencias que tengo que dar en otros lugares, trabajos que ya tengo de continuidad, como por ejemplo en Rio con Nanci de Oliveira, en Pelotas con Lúcio Menezes, en Alfenas que también ya tenemos un trabajo consecutivo y todas las cosas que tengo aquí en Campinas, como el Laboratório de Arqueología Pública.

\section{I.B.: Es posible hacer una comparación entre el desenvolvimiento de la Arqueología Pública en Brasil y en Cuba?}

L.D.:

Bueno yo te diría que no podríamos hablar de la Arqueología Pública específicamente. Vamos primero hablar de la Arqueología. Una comparación es diferente, acuérdate que nosotros somos un pequeño país y ustedes son un gran país. Pero tenemos una cosa en común, y es que a nadie le interesa, ni en Cuba ni en Brasil, la Arqueología. La Arqueología como ciencia, como un trabajo científico de desarrollo. Todo el mundo piensa que la Arqueología es hacer excavaciones, sacar cositas, ir a las cuevas, sacar joyas, maravillas y toda esa serie de cosas que no son Arqueología. O sea, no estamos viendo la Arqueología a partir de Indiana Jones, esa es la contra de la Arqueología de verdad. Arqueología es una ciencia social, una ciencia que ayuda a reconstruir la historia a partir de fuentes diferentes, de fuentes que no son escritas, y que son tan válidas como las escritas, pero que hay que saber para descifrar cada una de esas cosas 
muchísimas otras disciplinas que ayudan a trabajar, como la cerámica, la geografía, etc. Es una carrera que debe ser una carrera universitaria, y ahí es donde está el problema. Ninguna de nuestras universidades, tanto cubanas cuanto brasileñas, entienden el concepto de una carrera universitaria de Arqueología. Entienden la Arqueología como partes, partes de otras carreras, partes que entran dentro de otras carreras. En realidad no estamos formando arqueólogos, estamos formando personas que les interesa la Arqueología. Hay una circunstancia muy importante y que los países tienen que tener claro en esa circunstancia, la ley emitida por la Unesco y por veces las leyes de patrimonios emitidas por los propios países, exigen que el trabajo arqueológico se realice en cada uno de los movimientos de tierra que se hagan. Pero si tu no creas personal para ese trabajo, estas creando una clase de enredo tremendo, porque hay gente que está haciendo Arqueología privada, Arqueología de contrato, pero los componentes de esos mecanismos también están mal formados. O sea tú tienes que lograr tener una visión clara de que hay que hacer, aun que sea en el último pueblo de Brasil, una carrera. Hacer un proceso docente de estudio de la Arqueología. En estos días, en el congreso de $S A B$, estuve conversando con una profesora de nombre Lucía, que está trabajando en el IPHAN específicamente con eso, o sea, las necesidades de la Arqueología. E yo le decía que por lo que hay que empezar es por la parte docente. Si tu no creas el personal correctamente tú no puedes crear más nada, o sea, ni puedes crear los primeros profesionales que después te van a servir de maestros, ni puedes hacer más nada. Tal vez el primer curso te pase mucho trabajo, pero el segundo ya tienes estudiantes que están graduados, gente que se va desarrollando, pero van a seguir una línea de estudios docentes como las hay en España, hay en otros países europeos, en Estados Unidos también hay algunas carreras, pero en América Latina y en el Caribe no hay ninguna universidad que tenga esto, excepto México. 